\title{
An investigation of the relationship between environmental factors and job satisfaction in intensive nursing, with particular reference to spinal trauma
}

\author{
O Nugent BSc MA MClinPsych, ${ }^{1} \mathrm{C}$ A Glass BSc MClinPsych PhD CClinPsych, ${ }^{2} \mathrm{~K}$ R \\ Krishnan MB FRCS, ${ }^{3} \mathrm{~J}$ D Bingley $\mathrm{RGN}^{4}$ \\ ${ }^{1}$ Clinical Psychologist, Clinical Psychology Department, St Mary's Hospital, Whitworth \\ Park, Manchester M13 OJH; ${ }^{2}$ Principal Clinical Psychologist, ${ }^{3}$ Consultant in Spinal \\ Injuries, ${ }^{4}$ Senior Sister and Care Coordinator, Mersey Regional Spinal Injuries Centre, \\ Southport General Infirmery, Pilkington Road, Southport PR9 OHY, England.
}

The literature concerning the effects of stress on health service professionals has increased rapidly over the past 10 years (eg Holland et al, ${ }^{1}$ Koran et al, ${ }^{2}$ Stone et $\left.a l^{3}\right)$. The potential sources of such stresses are briefly reviewed and the involvement of the working environment as a source of stress is highlighted. The present investigation has examined the experience of 3 groups of nurses, working in spinal injuries, head injuries, and general medicine, using a standardised questionnaire devised by Moos. ${ }^{4}$ Significant differences were found between the 3 nurse groups on 3 subscales of the test (autonomy, innovation, and comfort), and the implications of the findings are discussed.

Key words: work environment; spinal injuries; stress; burnout.

\section{Introduction}

The chronic stress faced by staff on patient care units in general hospitals is an issue which is being increasingly raised in healthcare settings, with researchers in the area reporting links between work stress, lowered morale, impaired performance and high rates of absenteeism and turnover among nursing and other healthcare staff. ${ }^{2}$

Other reseachers (eg Cherniss and $\mathrm{Kratz}^{5}$ ) have shown how stressful work settings can compromise the quality of patient care by lowering motivation and contributing to staff 'burnout', also noting that the responsibility for acutely ill patients, the emotional climate surrounding illness and the often perfectionist expectations of healthcare staff are all implicated in staff distress.

Staff constitute part of the social environment which plays an important role in determining the behaviour of their patients ${ }^{6}$ and several studies have found support for such an interactive effect. ${ }^{7,8}$ For example, Dorr et $a l^{9}$ indicated that high morale

Correspondence: Dr C A Glass. amongst auxiliary psychiatric nurses was linked to working in a treatment environment characterised by organisation and clarity, a practical orientation, and an emphasis on mutual support amongst patients.

Holland et al $^{1}$ similarly put forward the view that a highly centralised, hierarchical organisation is often associated with regimented, impersonal patterns of care; such custodial practices resulting in patients being perceived as more passive. An overwhelming finding of research in this area is that patient improvement is linked to how satisfied staff are with their jobs. Furthermore, it is suggested that staff attitudes are enhanced by improved patient functioning as it promotes staff/patient cooperation in treatment, which has benefits for both groups.

Healthcare work climates have, similarly, been linked to employee morale, performance and turnover, Stone et $a l^{3}$ suggested that nurses who report high job autonomy and task clarity tend to be less alienated and emotionally exhausted, while nurses who see their work setting as supportive and innovative develop a greater sense of personal accomplishment. In addition, it seems 
work settings characterised by high peer group support can make demanding patient care situation less threatening.

Conversely, staff who report role ambiguity and lack of influence in decision making are more likely to experience poor morale and detachment. ${ }^{10}$

Job performance is affected by a number of other factors which are discussed individually below.

\section{Supervisory style and performance}

Duxbury et al ${ }^{11}$ considered that supervisory practices are of particular importance in employee satisfaction and job performance; job morale being higher when supervisors are seen as supportive and oriented towards open communication. Similarly, other researchers ${ }^{12,13}$ suggest that job dissatisfaction increases as nurses experience less independence and decision making power in their work. However, the impact of supervisory style on job performance may be moderated to some extent by the administrative climate of a particular hospital. Investigating this issue, Sheridan et al ${ }^{14}$ found that senior nurses with an assertive leadership style had a positive influence on performance in hospitals with a strong performance reward climate (ie policies that resulted in clear work goals and staff expectations for good job performance). In hospitals where performance was weakly rewarded, the senior nurses' assertiveness resulted in poorer staff performance.

\section{Organisational communication and performance}

Synder and Morris ${ }^{15}$ indicate that perceived communication processes are also related to objective measures of performance at the organisational level. These authors investigated 4 aspects of communication in 12 District Health Authorities and found that more positive evaluations of the quality of supervision and sharing of job related information were associated with lower work loads and higher organisational efficiency.

The role of personal factors

Job challenge and enrichment seem to benefit most employees, but those who have high 'growth needs' react more positively to it. ${ }^{15}$ Similarly, role clarity appears to benefit the performance of competent employees more than those of lower competence. ${ }^{16}$

The present study was concerned with evaluating some of the findings of an earlier study by Krishnan et al ${ }^{17}$ which investigated some of the potential causes of high turnover rates for nursing staff in a spinal injuries unit. Whilst these rates were comparable to those noted in other spinal injuries centres, they were significantly higher than the rates for other similarly sized and staffed units. It was noted that 'it was unclear whether such a high rate of turnover was due to difficulties encountered by individual members of staff in dealing with the patient population or was a function of the working environment on the unit itself'.

As literature in other areas had shown that environmental effects are associated with stress, which was often implicated in absenteeism and high turnover rates, the current investigation therefore centred on an examination of the effects of social climate in a number of nursing settings, in an attempt to establish whether environmental systems were significantly related to staff morale and job satisfaction.

\section{Method}

A total of 73 nurses, from 3 different hospitals were involved in the study (Table I). Each was requested to provide some brief demographic details, and complete a modified version of the Work Environment Scale, ${ }^{4}$ anonymously. Clinical psychologists in post at all 3 hospitals were approached, and their help enlisted in the administration of the questionnaire.

The two specialist units SIU and HIU, are specific regional spinal and head injury centres in the Mersey Region. The SIU was sited in accommodation built in the late nineteenth century and was due for imminent closure. The HIU was sited in modern purpose built accommodation, completed in the early 1980s. The GMW essentially dealt with cardiovascular and respiratory disord- 
Table I Distribution of nurses involved in the study

\begin{tabular}{lcc}
\hline Number of nurses & $\begin{array}{c}\text { Total complement } \\
\text { in post }\end{array}$ & $\begin{array}{c}\text { Compliance } \\
\text { (\%) }\end{array}$ \\
\hline 26 from a regional spinal injuries unit ward (SIU) & 35 & 74 \\
27 from a general medical ward (GMW) & 31 & 87 \\
20 from a regional head injuries unit ward (HIU) & 28 & 71 \\
\hline
\end{tabular}

ers, and was based in recently refurbished accommodation.

\section{Design}

The role of environmental factors (including patient characteristics) in job satisfaction on a spinal injury unit was assessed. Comparisons were made with a head injury unit and general medical ward. Details of the 2 questionnaire measures used are discussed in more detail below.

\section{Demographic details}

Information was requested on sex, age, marital status, parental status, number of children, ages of children, professional status and length of time worked on present unit. Individuals were also asked if they had previous experience of working on any of the following units: spinal injuries, head injuries, or general medical ward; and whether they intended to leave the unit within the next 12 months.

\section{Work environment scale (WES)}

Minor modifications were made to the scale to make the role definitions more relevant to the UK health service settings. For example, an explanatory note at the beginning of the questionnaire suggested that staff substitute the term 'nurse manager' for supervisor. The work environment scale is a standardised measure composed of 90 true/ false items that evaluate 10 dimensions of the social environment of work settings. The $\mathrm{R}$ (real) form of that scale used in this study measures perceptions of the existing work environment.

These 10 dimensions fall into 3 broad groups: (i) relationship dimensions; (ii) personal growth/goal orientation dimensions; and (iii) system maintenance/change dimensions.
The relationship dimensions are measured by the subscales: involvement, peer cohesion, and supervisor support. Together, these subscales investigate the extent to which employees are friendly to and supportive of one another, and the extent to which management is supportive of employees and encourages them to support one another.

The personal growth/goal orientation dimensions are measured by the subscales: autonomy, task orientation, and work pressure. They assess the extent to which employees are encouraged to be self sufficient and to make their own decisions; the degree of emphasis on good planning, efficiency and getting the job done; and the degree to which pressure of work and time urgency dominate the work setting.

The system maintenance/change dimensions are measured by the subscales: clarity, control, innovation and physical comfort. Together, they measure the extent to which employees know what to expect in their daily routines; how explicitly rules and policies are communicated; the extent to which management use rules and regulations to keep employees under control; the degree of emphasis on variety; change and new approaches; and the extent to which physical surroundings contribute to a pleasant work environment.

\section{Results}

Twenty-six spinal injuries staff, 27 general medical staff, and 20 head injuries staff completed both parts of the investigation. Five of the spinal injuries sample had to be excluded, due to inadequate completion of the WES. The compliance rate of this group is therefore reduced from $74 \%$ to $60 \%$. 
For purposes of clarity, results from the demographic data questionnaire and the work environment scale (WES) data are described separately in the following sections.

\section{Demographic data}

A summary of the findings of this section of the investigation are shown in Table II. The majority of nurses in all 3 settings were female $(96 \%)$. Both the SIU and HIU tended to employ more mature staff, neither employing anyone under 20 years old. The majority of SIU and HIU staff were married, with equal numbers of GMW staff being either married or single. SIU and HIU staff were more likely to be parents than GMW staff, again a probable reflection on the age of these 2 groups. GMW and HIU staff childrens' ages clustered in the younger and older age bands, with SIU staff producing a more even pattern across the 3 categories.

There were marked differences between units regarding professional status, with the majority of staff on the GMW being unqualified (this term refers to auxilliary nurses, and students in training). The SIU had fewer unqualified staff and the HIU least of all (only 5\%). Conversely the HIU had the highest number of staff at the grade of sister.

The majority of GMW staff had worked there for less than one year, whereas the majority of SIU staff worked there for a period of $1-5$ years. By contrast HIU staff were evenly spread across a 15 year span and were the only group to have staff in post for more than a 15 year period. Examination of the mean scores suggest that the SIU staff were in post 4 years, and the HIU staff 5 years, longer than the GMW staff.

The majority of staff in all 3 groups did not want to leave their present post for at least 12 months, although GMW staff appeared most uncertain about this decision.

In summary, therefore, demographic factors were found to be interrelated for all 3 groups. SIU staff were more likely to be married, work with other highly qualified staff and to have between one and 5 years' experience of working on the unit, with the majority not wishing to leave their present post. GMW staff tended to be younger than either of the other 2 groups and were

Table II Demographic characteristics of the sample

\begin{tabular}{llrrr}
\hline & & SIU & GMW & HIU \\
\hline Age & -20 & 0 & 14 & 0 \\
& $21-30$ & 38 & 48 & 31 \\
& $31-40$ & 27 & 18 & 36 \\
Marital staus & $40+$ & 33 & 18 & 31 \\
& Married & 75 & 40 & 57 \\
Professional status & Single & 15 & 40 & 36 \\
& Separated/other & 10 & 18 & 5 \\
& Unqualified & 22 & 55 & 5 \\
Time on unit (yrs) & SEN & 33 & 11 & 26 \\
& SN & 16 & 25 & 26 \\
& Sr & 27 & 7 & 42 \\
& -1 & 5 & 59 & 21 \\
& $1-5$ & 50 & 18 & 26 \\
Job change (within next 12 months) & $5-10$ & 20 & 22 & 15 \\
& $15+$ & 0 & & 15 \\
& Not stated & 25 & 0 & 23 \\
& Yes yon years on unit) & 6 & 2 & 7 \\
& No & 28 & 29 & 21 \\
& Unsure & 57 & 48 & 63 \\
& & 14 & 22 & 15 \\
\hline
\end{tabular}


equally likely to be married or single. A large proportion of this group were unqualified and had spent less than a year on the ward. In addition this group seemed most uncertain about changing their job within the next 12 months. Finally, the HIU staff (as with the SIU staff) tended to be older and married. There were few unqualified staff on the unit and it had the highest number of staff at senior grade (sister). Staff had worked on the unit for a period spanning 1-15 years, and were least likely of the 3 groups to want to change their job.

\section{Work Environment Scale results}

There was considerable variation both within and between groups in how they responded to items on the WES. Mean scores on each subscale were calculated for each group, and the results, in comparison with the staff norms provided by the scale's authors, are illustrated in Figure 1. Figure 1 indicates that HIU staff related their environment most positively overall, with GMW staffs' ratings slightly lower, and that the SIU staff rated their environment least favourably of all. However, there were

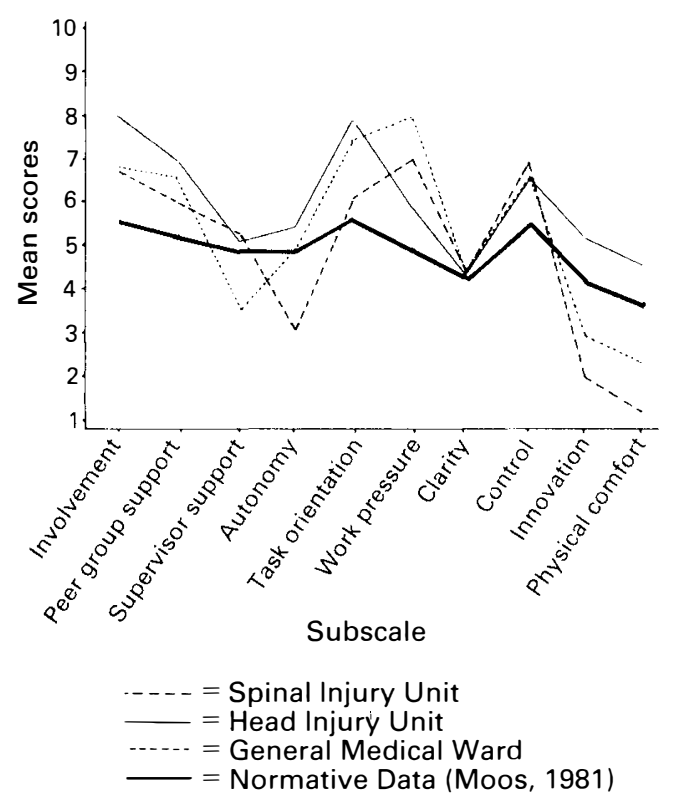

Figure 1 Mean scores on the WES subscales for each patient group compared with the norms provided by Moos. ${ }^{4}$ considerable differences between the responses of the 3 groups to the individual subscales, and these are outlined below.

\section{Spinal injuries unit staff}

SIU staff rated their work environment lower than their counterparts on 5 subscales. These were: peer group cohesion, task orientation, autonomy, innovation and comfort. Scores on the latter 4 were lower than the standardised averages for this scale. SIU nurses were, however, highly committed to their jobs and reported that they received adequate support from their supervisors. The SIU environment was seen as less efficient and well planned regarding individual tasks, than either the GMW or the HIU. Work pressure was seen as high and, like the other 2 units, there was a lack of clarity about rules and policies. (This was the only subscale where all 3 groups of nurses responded in the same way). In addition, autonomy in decision making was rated as low. SIU staff saw supervisors as maintaining control, mostly through the use of regulation and, in general terms, staff saw little possibility of change (innovation). Finally, ratings of physical comfort by SIU staff were the lowest recorded over all 10 subcales by all 3 groups.

\section{Head injuries unit staff}

This group rated their work environment most positively out of the 3 groups. They were involved and committed to their jobs and had good peer relationships. Supervisor support was adequate and the unit was rated highly on good planning and efficiency. Autonomy was rated as being above average and was higher than for the other 2 groups. However there was vagueness about rules and policies and a high emphasis on controlling staff through use of rules and regulations. Lower than average ratings were given on how innovative and how physically comfortable the surroundings were, but both these ratings were higher than for the other 2 groups.

\section{General medical ward staff}

Nurses appeared committed to their jobs and had good relationships with peers. Supervisor support was well below average 
and very much lower than for the other 2 groups. Autonomy was rated in the average range and the unit was rated highly on planning and efficiency. However, pressure of work was given the highest rating across all 3 groups. As with the other 2 nurse groups, GMW nurses held the view that there was vagueness about what was expected of them and saw themselves as being mainly controlled through the use of rules and regulations. Innovation and physical comfort were rated low as in the other 2 groups.

Statistical analysis of the 10 subscales on the WES, showed that there were significant differences between the 3 nurse groups on 3 of the subscales and the results of these analyses are outlined in Table III.

Autonomy relates to the personal growth dimension of the WES. It measures how strongly people are encouraged to make their own decisions and be self sufficient. Innovation and comfort both constitute part of the system maintenance/change dimension of the WES, measuring the degree of emphasis on change and new approaches and how physically comfortable the environment is seen to be.

The mean scores for the 3 staff groups would indicate that the HIU environment is seen as significantly more satisfying than the other 2 settings on each of these 3 points.

\section{Discussion}

Spinal injury nurses were found to be most pessimistic about their workplace. Earlier studies (eg Krishnan et $a l^{17}$ ) had investigated whether the intensive nature of work in spinal injuries settings was responsible for lowered morale and, as a consequence, the high staff turnover rates experienced in these units. The intensive nature of spinal injury nursing, in itself, does not appear to provide a causal explanation of dissatisfaction as head injury nurses (also working in an intensive nursing setting) rated their environment most positively overall. Given the advancing age of the current spinal injuries unit it is likely that the physical surroundings do have an adverse effect on nursing morale, although it is unclear whether this is a primary or secondary factor associated with turnover.

SIU and HIU staff tended to be older, married and have children ( $75 \%$ of SIU staff being parents). Factors such as these may explain why staff are reluctant to change their jobs: Fawzy et al ${ }^{18}$ noted that young single nurses are more likely to seek other experiences such as furthering their education or starting a family, with such tasks more likely to have been accomplished by older nurses with families.

When responses to the question about future job change are examined, almost one third of SIU and GMW staff replied that they were likely to look for alternative employment in the next 12 months.

From data relating to length of time on the unit, it would appear that GMW staff have higher rates of turnover than SIU staff. This is, however, misleading as the GMW had the highest number of unqualified (auxiliary and trainee) staff. In addition, 'unqualified' includes student and pupil nurses, who may have had to leave the ward through necessity, in terms of nurse train-

Table III Significant differences between the 3 nurse groups on the Work Environment Scale subscales

\begin{tabular}{lcccrrrr}
\hline Subscale & $\begin{array}{c}\text { SIU } \\
(\overline{\mathrm{x}})\end{array}$ & $\begin{array}{c}\text { HIU } \\
(\overline{\mathrm{x}})\end{array}$ & $\begin{array}{c}\text { GMW } \\
(\overline{\mathrm{x}})\end{array}$ & DF & F & $\begin{array}{c}\text { Standard } \\
\text { error }\end{array}$ & $\mathrm{P}$ \\
\hline Autonomy & 3.5000 & 5.5000 & 4.6296 & 2 & 10.87 & .1910 & .0001 \\
Innovation & 2.5000 & 4.6500 & 3.0741 & $\begin{array}{r}2 \\
2\end{array}$ & 7.18 & .2485 & .0015 \\
Comfort & 1.1818 & 4.0000 & 2.3704 & $\begin{array}{r}66 \\
2\end{array}$ & 13.04 & .2508 & .0001 \\
\hline
\end{tabular}


ing, rather than reflecting true turnover. Although pessimism about the work environment is highest in the spinal nurse group, this is not reflected in an inordinately high level of desire to seek alternative employment.

The work environment scale results indicated significant differences on 3 of the subscales (autonomy, innovation and comfort) for the 3 staff groups.

Moos and Schaefer ${ }^{19}$ suggested that job formalisation and centralised decision making (typical of most healthcare settings) is linked to lack of support and less emphasis on autonomy and clarity. Furthermore, they suggested that nurses who work on units where patients have more complex medical problems are more likely to engage in demanding tasks and to report more autonomy in decision making. Whilst all 3 groups of nurses in this study were involved and committed to their jobs (according to the WES scores), SIU and HIU staff gave differential support for this finding in terms of autonomy, although both these groups could be described as working with patients with complex medical problems. HIU staff lend some support to this view, showing a relatively high degree of autonomy, whilst SIU staff would appear somewhat atypical in this respect, showing the lowest level of autonomy of the 3 groups and lower than the average score in the standardisation data. ${ }^{4}$

Stone et $a l^{3}$ suggested that autonomy and innovation in the work setting were important factors in terms of reducing alienation and emotional exhaustion respectively, and in developing a greater sense of personal accomplishment. However moderating variables such as good supervisor and peer group support are thought to alleviate such a situation. All 3 groups in the present study showed average or above average levels of both of these forms of support. This may explain why some nurses (SIU staff in particular) tolerate low levels of autonomy and innovation, because the degree of support they receive from colleagues is of such a high standard.

In terms of comfort all 3 groups of nurses rated their environments as lower than the provided normative data on this subscale.
This is partly understandable for the SIU staff as the centre is not set in purpose built accomodation. (This is likely to occur in mid 1991, and investigations are already underway to reassess the factors in the present investigation at this time).

The aim of the present investigation was to establish whether environmental systems were significantly related to staff morale and job satisfaction. Although there are trends towards higher levels of satisfaction amongst the HIU group in comparison with the GMW and SIU staff groups which in part reflect the decreasing quality of environmental standards (purpose built, modified, and low quality for the HIU, GMW and SIU respectively) the causal relationship remains unclear due to the interaction between environmental, intra- and interdependent personal variables. Whilst the present study yields useful information central to understanding the role of environmental factors in staff job satisfaction, many questions remain unanswered. As Savicki and Cooley ${ }^{20}$ note, 'a complete understanding of the relationships between the environment (and burnout) must take into account the subtle differences in environmental demands (and burnout) reactions created by role differences within the same helping agency'. Similarly, Locke ${ }^{21}$ emphasised the interaction between the person and their job: 'The causes of job satisfaction are not solely in the job nor in the (person) but lie in the interaction between the two'. In terms of improving healthcare settings, Shinn and Morch $^{22}$ propose a tripartite model for coping with work stress: (1) coping strategies for use by individuals, such as setting limits to one's own activities or focusing on positive aspects of the work; (2) strategies undertaken by groups, such as mutual support groups; and (3) strategies initiated by agencies, such as job designs or provision of recreational facilities.

It is the aim of the current investigators that such strategies will be implemented in the SIU, in order to capitalise on the high degree and quality of staff support available through peers and supervisors. Comprehensive post qualification education and support groups are being established, with the aim of providing staff with the opportun- 
ity to raise particular issues and to share knowledge about work pressures and coping strategies.

The difficulties faced by staff are not intractable. Administrators should consider a shift in their focus of attention from attracting new staff to keeping existing staff, and the present study highlights some of the ways in which this may be affected. As Moos and Schaefer ${ }^{19}$ succinctly state: 'Heathcare administrators and staff must address the problem of how to meet consumer demands for affordable quality care. Part of this solution lies in improving staff morale and performance via the creation of more humane work environments'.

\section{References}

1 Holland T, Konick A, Buffum W, Smith MK, Petchers M (1981) Institutional structure and resident outcomes. J Health Soc Behav 22: 433-444.

2 Koran L, Moos R, Moos B, Zasslow M (1983) Changing hospital work environments: an example of a burns unit. Gen Hosp Psychiatry 5: 7-13.

3 Stone GL, Jebsen P, Walk P, Belsham R (1984) Identification of stress and coping skills within a critical care setting. West J Nurs Res 6: 201-211.

4 Moos RH (1981) Work Environment Scale Manual. Consulting Psychologists Press, Palo Alto, California.

5 Cherniss C, Kratz D (1983) The ideological community as an antidote to burnout in the human services. In: Farber B, editor. Stress and Burnout in the Human Service Professions. Pergamon Press, New York: $192-212$.

6 Thomas M, Benton M, Cullen C (1982) Take a look at your ward. Nurs Times 78: 1068-1070.

7 Kelman T, Chessan R (1962) Social context and symptom fluctuations. Psychiatry 25: $370-381$

8 Rapaport D (1962) New Perspectives on a Therapeutic Community. Tavistock Press, London.

9 Dorr D, Honea S, Pozner R (1980) Ward atmosphere and psychiatric nurses job satisfaction. Am J Comm Psychol 8: 455-461.

10 Maslach P, Jackson D (1982) Burnout in health professions: a social psychological analysis. In: Sanders G, Suls J, editors. Social Psychology of Health and Illness. Earlbaum, Hillsdale NJ: 227-251.

11 Duxbury ML, Armstrong GD, Drew DJ Henly SJ (1984) Head nurse leadership style with staff nurse burnout and job satisfaction in neonatal intensive care units. Nurs Res 33: 97-101.

12 Decker FH (1985) Socialisation and interpersonal environment in nurses affective reactions to work. Soc sci Med 20: 499-509.

13 Gray-Toft PA, Anderson JG (1985) Organisational stress in the hospital: development of a model for diagnosis and prediction. Health Serv Res 19: 753-774.

14 Sheridan J, Vredenburgh D, Abelson M (1984) Contextual model of leadership in hospital units. Acad Mgt J 27: $57-78$.

15 Synder R, Morris J (1984) Organisational communication and performance. J Appl Psychol 69: 461-465.

15 Hackman JR, Oldham G (1980) Work Redesign. Addison-Wesley, Reading, Massachusetts.

16 McEnrue M (1984) Perceived competence as a moderator of the relationship between role clarity and job performance: a test of two hypotheses. Organ Behav Hum Perform 34: 379-386.

17 Krishnan KR, Glass CA, Jackson JF, Bingley JD (1988) Patient and nursing staff perceptions of working and living on a spinal injury unit. Paraplegia 26: 287-292.

18 Fawsey IF, Wellisch DK, Pasnau RO, Leibowitz B (1983) Preventing nursing burnout: a challenge for liaison psychiatry. Gen Hosp Psychiatry 5: 141-149.

19 Moos RH, Schaefer JA (1987) Evaluating work settings: a holistic conceptual framework. Psychol Health 1: 97-122.

20 Savicki V, Cooley E (1987) The relationship of the work environment and client contact to burnout in mental health-care professionals. J Coun Dev 65: 249-252.

21 Locke EA (1969) What is job satisfaction? Organ Behav Hum Perform 1: 309-336.

22 Shinn M, Morch H (1983) A tripartite model of coping with burnout. In: Farber BA, editor. Stress and Burnout in Human Service Professions. Pergamon Press, New York: 227-240. 